\title{
Ontogeny of Reactive Nitrogen Species Production by Blood Phagocytes in Pigs
}

\author{
P. ZELNíČKOVÁ ${ }^{1,2}$, M. FALDYNA ${ }^{1,2}$, J. ONDRÁČEK ${ }^{2}$, H. KOVÁŘ ${ }^{3}$, F. KOVÁŘ ${ }^{4,5}$ \\ ${ }^{1}$ Veterinary Research Institute, Department of Immunology, Brno, ${ }^{2}$ University of Veterinary and \\ Pharmaceutical Sciences Brno, Institute of Microbiology and Immunology, Brno, ${ }^{3}$ First Medical \\ Faculty, Charles University, Prague, ${ }^{4}$ University of Veterinary and Pharmaceutical Sciences Brno, \\ Institute of Physiology, Brno, ${ }^{5}$ Institute of Animal Physiology and Genetics, Academy of Sciences \\ of the Czech Republic, Brno, Czech Republic
}

Received October 19, 2006

Accepted December 17, 2006

On-line available January 2, 2007

\begin{abstract}
Summary
The aim of this work was to evaluate ontogeny of reactive nitrogen species (RNS) production by peripheral blood phagocytes in pig. Pig fetuses (55 and 92 days of gestation) and postnatal piglets $(1,3,8,17,31$ and 41 days after birth) were used. RNS production was measured by fluorescent probes diaminofluorescein-diacetate (DAF-FMDA) and dichlorofluorescein-diacetate (H2DCFDA). Levels of nitration of cell proteins were established by immunofluorescent detection of nitrotyrosine. Levels of plasma nitrites/nitrates were detected spectrophotometrically by Griess reaction. Nitric oxide production measured by DAF-FMDA in neutrophils decreased during postnatal life. Spontaneous RNS measured by H2DCFDA decreased from 55th day of gestation to the 41st day of life. Phorbol-12-myristate-13-acetate activated production decreased during postnatal life. Production of NO measured by DAF-FMDA in macrophages decreased from the 1st to 41st day after birth. RNS production measured by H2DCFDA in monocytes did not show any significant changes during ontogeny. The level of nitrotyrosine significantly decreased from the 3rd to 17th day. Levels of plasma nitrites/nitrates gradually decreased from the 55th day of gestation to the 41st day after birth. A temporary increase in all parameters occurred after weaning, but without any significance. In conclusion, RNS production has a decreasing trend during ontogeny and is transiently upregulated after weaning.
\end{abstract}

\section{Key words}

Blood phagocytes - Ontogeny - Reactive nitrogen species • Plasma nitrites/nitrates

\section{Corresponding author}

Petra Zelnickova, Veterinary Research Institute, Hudcova 70, 621 00 Brno, Czech Republic, Fax: +420-541-211-229, E-mail: zelnickovap@vfu.cz

\section{Introduction}

There is substantial evidence that the porcine immune system develops not only before birth but also during early postnatal life (Zelníčková et al. 2006). Development of acquired immunity in pig has recently been a relatively well-explored part of developmental immunology (Trebichavský et al. 1996, Kováŕů et al. 2002). On the contrary, there is very little information about both prenatal and postnatal ontogeny of natural immunity, especially mechanisms of defense against potential infection by phagocytes. The production of reactive oxygen and nitrogen species is one of the most important bactericidal mechanisms of phagocytic cells.

Nitric oxide can be produced by many cell types by action of two types of the enzyme nitric oxide synthase (NOS) (Forstermann et al. 1995). Under physiological conditions, only small amounts of NO by the constitutive, calcium-dependent isoform of NOS (cNOS) are produced. NO produced by cNOS plays a role as a regulator of vascular tone. cNOS is expressed mainly by endothelial cells and neurons. On the other hand, inducible NOS (iNOS) expressed by activated phagocytes plays crucial role in production of relatively high amounts of NO, which give rise to other, much more efficient reactive nitrogen species (RNS), e.g. peroxynitrite. RNS ensure the sufficient fight of phagocytes against bacterial pathogens (Fang 1997, Chakravortty and Hensel 2003).

There is very little and controversial information 

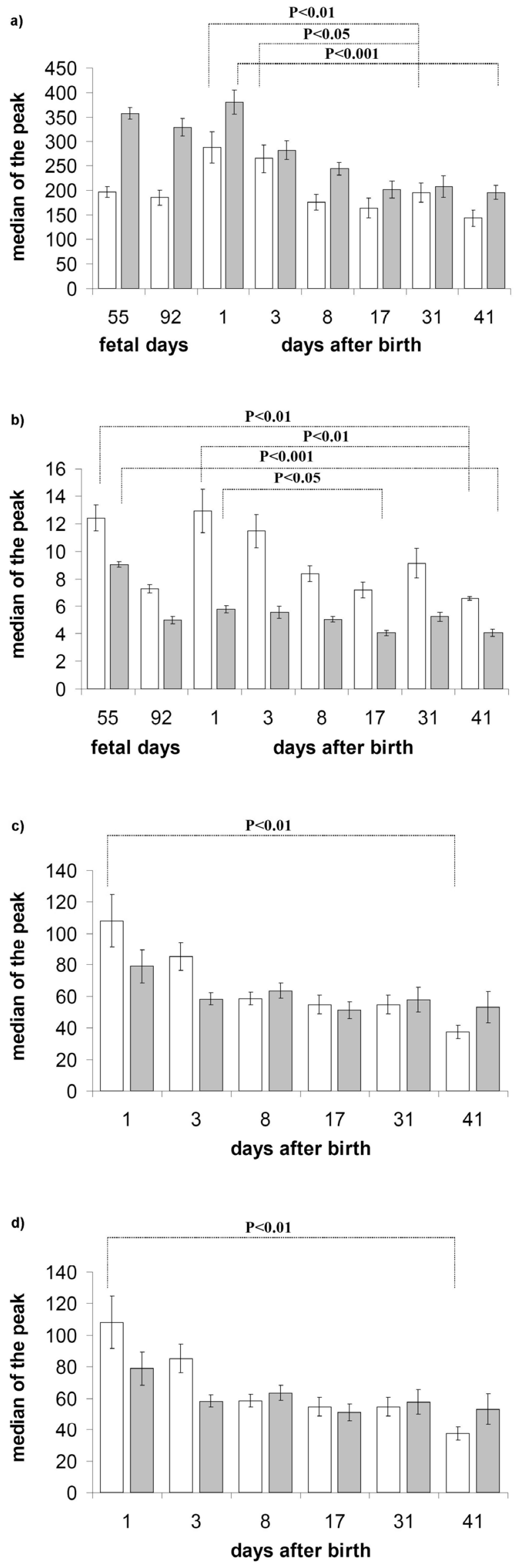

Fig. 1. In vitro production of reactive nitrogen species (RNS) by peripheral blood phagocytes during ontogeny in pigs. Nitric oxide detected by diaminofluorescein diacetate (DAF-FM DA, white bars) and other RNS detected by dichlorodihydrofluorescein diacetate $\left(\mathrm{H}_{2} \mathrm{DCF} \mathrm{DA}\right.$, grey bars) were measured in PMAstimulated neutrophils (a), non-stimulated neutrophils (b), PMAstimulated monocytes (c) and non-stimulated monocytes (d). RNS production was expressed as the median of the histogram peak in FL1 channel after gating of viable, propidium iodide (FL3 channel) negative and CD14 (FL2 channel) positive cells (final discrimination between monocytes and neutrophils was realized by their light scatter characteristics). Results are shown as mean of medians \pm SEM. Significant differences between pairs (Dunn's post-test) are marked in the Figure.

available about ontogeny of RNS production by phagocytes at present. Sherman et al. (1996) found that spontaneous, LPS, and IFN- $\gamma$ stimulated RNS production by rat alveolar macrophages in 3-day-old animals was twice as high as that by older animals (10 days old and adults). On the contrary, Lee et al. (2001) found that RNS production by rat alveolar macrophages stimulated in the same way was significantly lower in newborn rats in comparison to adult ones. However, production of RNS by blood phagocytes has not yet been assessed.

More information exists about ontogenesis of plasma nitrite or nitrate production. Plasma nitrite/nitrate may be formed nonenzymatically by ingestion of nitrites with food or may be formed by intestinal flora (Castillo et al. 1993). In fasting humans, it arises mostly from endogenously produced nitric oxide (Rhodes et al. 1995). Endogenously produced nitric oxide spontaneously changes to nitrite, which converts to nitrate when the reaction is catalyzed by hemoglobin (Ignarro et al. 1993). The basal and relatively constant plasma nitrite/nitrate levels are products of cNOS activities (Kleinbongard et al. 2003). However these levels can be greatly enhanced during antigenic challenge when iNOS from activated phagocytes become a major source of endogenous nitric oxide (Ergenekon et al. 2000).

Ontogeny of plasma nitrite and nitrate levels have been better documented than direct production of RNS by blood phagocytes. However, this is only via indirect detection, which may represent production of NO from other sources than blood phagocytes. Unfortunately, the results obtained by different investigators are controversial. While Endo et al. (2001) found that levels of plasma nitrites/nitrates increase during the first few days of life in children, Blum et al. (2001) found a strong decrease in calves. These data further suggest that there may exist species-specific differences in ontogeny of plasma nitrites and nitrates. As far as we know, there is only one publication referring to increased fetal plasma 
nitrate levels in ovine fetuses (Yang et al. 1996). Other data related to prenatal ontogeny are limited to a comparison of preterm and term-born children (Honold et al. 2000). Moreover, no data about the ontogeny of plasma nitrites/nitrates in pig have been published yet.

Protein tyrosine nitration in neutrophils occurs when RNS, mostly peroxynitrites are produced (Ischiropoulos 1992). Immunohistochemical detection of nitrotyrosine can be used as another method for the evaluation of in vivo RNS production.

The aim of the present study was to evaluate production of RNS by peripheral blood phagocytes in pigs during prenatal and postnatal ontogeny.

\section{Methods}

\section{Animals and blood sample collection}

Piglets on days 55 (7 piglets) and 92 (5 piglets) of gestation, taken from two sows which underwent hysterectomy under halothane inhalation anesthesia, were used in this study. Eight postnatal piglets from two litters were used at the age of $1,3,8,17,31$ and 41 days. The sows were separated from piglets after weaning on day 28 and piglets were then kept together in one pen. The animals were used under the agreement of the Branch Commission for Animal Welfare of the Ministry of Education, Youth and Sports of the Czech Republic.

The blood from fetuses was obtained by puncture of the umbilical cord vein. Peripheral blood from postnatal piglets in the volume of 3-4 $\mathrm{ml}$ was collected on heparin (20 IU/ml, Zentiva, Czech Republic) by puncture of the jugular vein.

\section{Assays for determination of nitric oxide production \\ Flow cytometric measurements}

Intracellular fluorescent probes diaminofluorescein diacetate (DAF-FM DA, Invitrogen, USA) and dichlorodihydrofluorescien diacetate $\left(\mathrm{H}_{2} \mathrm{DCF}\right.$ DA, Sigma-Aldrich, USA) were used for flow cytometric detection of reactive nitrogen species produced by blood phagocytes (neutrophils and monocytes).

The whole blood $(60 \mu \mathrm{l})$ was mixed with either $15 \mu \mathrm{l}$ of DAF-FM DA (final concentration $10 \mu \mathrm{mol} / \mathrm{l}$ ) or $\mathrm{H}_{2}$ DCF DA (final concentration $5 \mu \mathrm{mol} / \mathrm{l}$ ) and $15 \mathrm{ul}$ of phorbol-12 myristate-13 acetate (PMA, Sigma-Aldrich), which was used as stimulator (final concentration 200 $\mathrm{nmol} / \mathrm{l}$ ). All solutions were diluted in HBSS (Sigma Aldrich) in $3 \mathrm{ml} \mathrm{FACS}$ tubes and incubated in $37^{\circ} \mathrm{C}$ water bath in the dark for $20 \mathrm{~min}$. In blank samples, the fluorescent probes were replaced by HBSS. The reaction was stopped after $20 \mathrm{~min}$ and red blood cells were lysed using $3 \mathrm{ml}$ of $5-8^{\circ} \mathrm{C}$ cold hemolytic solution $(154 \mathrm{mmol} / 1$ ammonium chloride, $10 \mathrm{mmol} / \mathrm{l}$ potassium bicarbonate) (Sigma-Aldrich). After centrifugation $(600 \mathrm{x} \mathrm{g}, 7 \mathrm{~min}$, $0{ }^{\circ} \mathrm{C}$ ) and removal of the supernatant, $5 \mu \mathrm{l}$ of PEconjugated anti-human CD14 antibody (clone Tük4, Serotec, UK) was added and the solution was incubated in ice-cold water bath in the fridge for $15 \mathrm{~min}$. After the next washing with ice-cold PBS and addition of propidium iodide (Sigma-Aldrich), the samples were immediately measured in flow cytometer (FACS Calibur, Becton Dickinson, USA). Off-line analysis was performed by Summit Software, version 4.0 (Dako Cytomation, Denmark) and WinMDI, version 2.8 (http://facs.scripps.edu/software.html).

For expression and statistical evaluation of results, the median of the positive DAF-FM DA or $\mathrm{H}_{2}$ DCF DA (FL1 channel) peak of either the neutrophil or monocyte subpopulations was evaluated after gating of viable cells (propidium iodide negative cells - FL3 channel). Neutrophils and monocytes were identified according their light scatter characteristics and positivity in FL2 channel (CD14-positive cells).

\section{Spectrophotometrical detection of plasma nitrites and nitrates}

Concentrations of plasma nitrites and nitrates produced in vivo were detected by the Griess reaction (Sun et al. 2003, Trebichavský et al. 2001). The blood sample was centrifuged $\left(1000 \mathrm{x} \mathrm{g}, 10 \mathrm{~min}, 22^{\circ} \mathrm{C}\right)$ to obtain blood plasma. Then $10 \mu \mathrm{l}$ of blood plasma diluted 1:5 by deionized water was mixed with $20 \mu \mathrm{l}$ of 0.31 $\mathrm{mol} / 1 \mathrm{PBS}$ (Sigma-Aldrich), $10 \mu \mathrm{l}$ of $0.86 \mathrm{mmol} / 1$ NADHP, tetrasodium salt (Roche, Germany), $10 \mu \mathrm{l}$ of $0.11 \mathrm{mmol} / \mathrm{l}$ flavin adenine dinucleotide, disodium salt (Sigma-Aldrich), and $10 \mu \mathrm{l}$ of $0.1 \mathrm{IU}$ nitrate reductase from Aspergillus sp. (Roche) and incubated in the dark at room temperature for $60 \mathrm{~min}$. Then $60 \mu \mathrm{l}$ of Griess reagent ( $1 \%$ sulphanilamide, $5 \% \mathrm{H}_{3} \mathrm{PO}_{4}$ and $0.1 \%$ 2-(1-naphthylamino ethylamine) (all Sigma-Aldrich) was added to each sample. Samples were measured spectrophotometrically (Lambda 11, Perkin-Elmer, USA) at the wavelength of $540 \mathrm{~nm}$. Concentrations of nitrites/nitrates in each sample (expressed in $\mu \mathrm{mol} / \mathrm{l}$ ) were read from the calibration curve. The calibration curves were determined using different concentrations of sodium nitrite and sodium nitrate (both Sigma-Aldrich) solutions by the same procedure as blood samples. 
Immunofluorescent detection of nitrotyrosine

Nitrotyrosine was detected in neutrophils by indirect immunofluorescent staining (Viera et al. 1999). Neutrophils, isolated by discontinuous density gradient Histopaque 1077/Histopaque 1119, were sliced on the cover slips by cytocentrifugation. The cells were fixed in $4 \%$ paraformaldehyde in PBS for $15 \mathrm{~min}$ and permeabilized with $0.1 \%$ Triton $\mathrm{X}-100$ for $15 \mathrm{~min}$. Blocking was performed by $10 \%$ donkey serum in PBS for one hour. The samples were then incubated with antinitrotyrosine antibodies (Upstate, USA) overnight at room temperature. On the next day, samples were incubated for one hour with FITC conjugated donkey anti-rabbit secondary antibodies. Cell nuclei were stained by propidium iodide. Preparates were mounted with VectaShield H-1000 mounting medium (Vector Laboratories, USA). The intensity of fluorescence for each cell was expressed semiquantitatively as $25 \%$, $50 \%, 75 \%$ and $100 \%$ positivity and then the mean percentage value for all 200 neutrophils was calculated.

\section{Statistical analysis}

Age-dependent changes were tested with the non-parametric ANOVA test (Kruskal-Wallis test) and with Dunn's post-test for the comparison of all pairs. All calculations were performed with MS-Excel (Microsoft Corp. Inc.) and Prizma ${ }^{\circledR}$ (Graph Pad Software Inc.) software.

\section{Results}

\section{Flow cytometric measurements}

Significant changes of RNS production in neutrophils (stimulated as well as nonstimulated) were detected during ontogeny. In monocytes, only stimulated production significantly changed. Some minor changes of RNS production were observed during prenatal ontogeny, but they were non-significant and without any correlation between stimulated and nonstimulated cells, or between DAF-FM DA and $\mathrm{H}_{2}$ DCF DA. Prenatal RNS production was detected in neutrophils only due to a presence of small numbers of white blood cells in blood of pig fetuses. During postnatal period, significant decreases in RNS production by neutrophils (stimulated as well as nonstimulated) and by stimulated monocytes occurred. Moreover, transitional increases in RNS production by neutrophils and by stimulated monocytes occurred after weaning; however, without any significance.

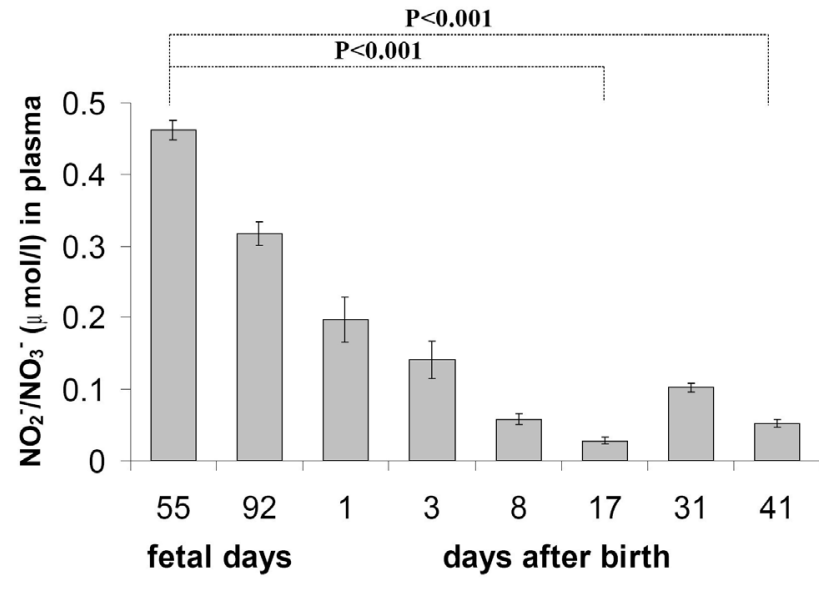

Fig. 2. Level of plasma nitrites/nitrates during ontogeny in pigs. Plasma nitrites/nitrates were measured spectrophotometrically by modified Griess reaction assay at $450 \mathrm{~nm}$. Absorbance was recounted to nitrites/nitrates (expressed in $\mu \mathrm{mol} / \mathrm{l}$ ) by calibration curve. Results are shown as mean \pm SEM. Significant differences between pairs (Dunn's post-test) are marked in the Figure.

\section{Production of RNS by activated neutrophils}

Production of RNS significantly changed during ontogeny (Kruskal-Wallis test for DAF-FM DA: $\mathrm{P}<0.01$; for $\mathrm{H}_{2} \mathrm{DCF}$ DA: $\mathrm{P}<0.001$ ) (Fig. 1a). No significant changes occurred during the prenatal period. Significant decrease was found during postnatal life (Dunn's posttest for DAF-FM DA between days 1 and 31 of age: $\mathrm{P}<0.01$; for $\mathrm{H}_{2} \mathrm{DCF} \mathrm{DA}$ between day 1 and 41 of age: $\mathrm{P}<0.001)$.

\section{Spontaneous production of RNS by neutrophils}

Production of RNS significantly changed during postnatal period (Kruskal-Wallis test for both DAF-FM and $\mathrm{H}_{2} \mathrm{DCF}$ DA: $\mathrm{P}<0.001$ ) (Fig. 1b). No significant changes occurred during prenatal period. Significant decrease was found in RNS production during postnatal life (Dunn's post-test for DAF-FM DA between days 1 and 41 of age: $\mathrm{P}<0.01$; for $\mathrm{H}_{2} \mathrm{DCF}$ DA between days 1 and 17 of age: $\mathrm{P}<0.05$ ).

\section{Stimulated and spontaneous production of RNS by monocytes}

Production of RNS (specifically NO measured by DAF-FM DA) significantly decreased during postnatal ontogeny (Kruskal-Wallis test: $\mathrm{P}<0.01$, Dunn's post-test between days 1 and 41 of age: $\mathrm{P}<0.01$ ). Postnatal production of RNS measured by $\mathrm{H}_{2} \mathrm{DCF}$ DA did not change (Fig. 1c,d). 


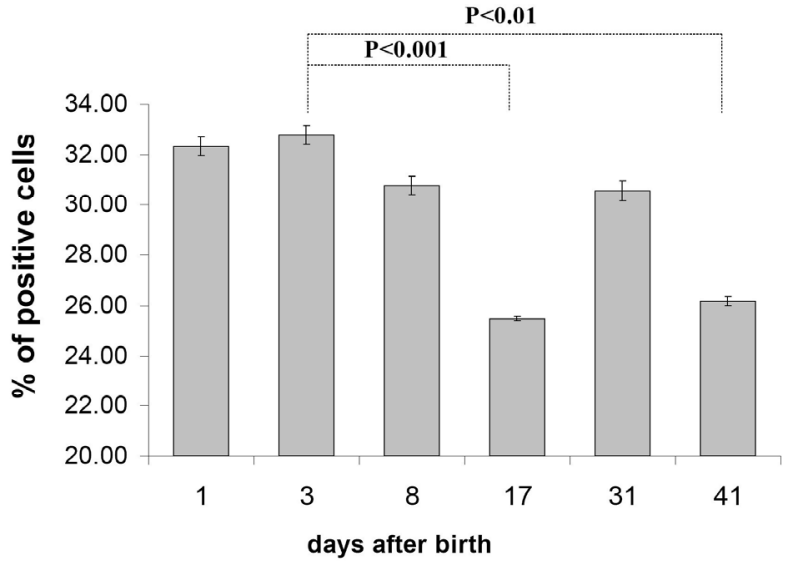

Fig. 3. Levels of nitrotyrosine in neutrophil granulocytes during postnatal ontogeny in pigs. Nitrotyrosine was detected by indirect immunofluorescent staining. Neutrophils were recognized by nucleus morphology after staining with propidium iodide. 200 neutrophils were evaluated. The intensity of fluorescence for each cell was expressed as $25 \%, 50 \%, 75 \%$ and $100 \%$ intensity of fluorescence and then the mean percentage value for all 200 neutrophils was calculated. Results are shown as a mean of percentage representation \pm SEM. Significant differences between pairs (Dunn's post-test) are marked in the Figure.

\section{Spectrophotometrical detection of plasma nitrites and nitrates}

Levels of plasma nitrites/nitrates significantly changed during ontogeny (Kruskal-Wallis test: $\mathrm{P}<0.001$ ) (Fig. 2). Gradual decrease occurred from day 55 of gestation to day 41 of postnatal life (Dunn's post-test: $\mathrm{P}<0.001$ ). Plasma nitrites/nitrates levels correlated with NO production by neutrophils during postnatal life including non-significant transient increase after weaning on day 31 of age.

\section{Immunofluorescent detection of nitrotyrosine}

The level of nitrotyrosine in neutrophil granulocytes showed significant decrease from day 3 to day $17(\mathrm{P}<0.01)$ and from day 3 to day $41(\mathrm{P}<0.001)$ of age (Fig. 3). Transient increase after weaning, though without significance, correlated with an increase of RNS and ROS production by neutrophils.

\section{Discussion}

The aim of the present study was to evaluate production of RNS during prenatal and postnatal ontogeny by peripheral blood phagocytes in pigs. Our previous data (Zelníčková et al. 2006) documented that the production of reactive oxygen species by blood phagocytes measured by chemiluminescence also decreased during postnatal ontogeny. In general, it would be more logical to expect that RNS production as a representative bactericidal mechanism in peripheral blood cells will have an increasing trend during ontogeny.

The non-significant increase in RNS production after weaning, which correlated with the increase of plasma nitrites/nitrates levels and content of nitrotyrosine in neutrophils, could be related to the activation of immunity after absence of lactogenic immunity, and consistent with the increase of antigenic pressure.

The production of RNS by neutrophils and monocytes after stimulation correlated with its spontaneous production. The RNS production depends on the amount of iNOS present in RNS-producing cells and on the availability of the substrate (L-arginine). It is likely that the 20 min stimulation with PMA used in the present study is not sufficient for increased iNOS expression, but only for elevation of the RNS production by the increasing substrate availability to present iNOS. It seems to be desirable to detect the content of iNOS in the phagocytosing cells as another parameter, which characterizes the NOS production but there is no commercially available monoclonal antibodies against porcine iNOS.

While there are no data about RNS production by blood phagocytes during ontogeny, more information is available about levels of nitrites/nitrates in blood or urine. However, almost all data arises from human model. The levels of plasma nitrites/nitrates were found to increase from birth to day 5 of life (Endo et al. 1996, 2001) with subsequent decrease until day 30 of age (Endo et al. 1996). A similar increase of nitrites/nitrates levels in children from days 1 to 4 of age in urine was observed by Tsukahara et al. (1997a). Other observations refer to the transient increase of urinary nitrites/nitrates in a later period - an increase from ages 1 week to 1 month with a subsequent decrease to 4 months of age (Tsukahara et al. 1997b). The reason for these observations was the developing intestinal flora, which is the source of plasma nitrites/nitrates. Our observations show decreasing plasma nitrites/nitrates during the whole early postnatal period, similar to the data from literature describing plasma levels of nitrites/nitrates in newborn calves (Blum et al. 2001).

The principal questions are what is the main source of plasma nitrites/nitrates during ontogeny and why are plasma nitrites/nitrates elevated during the early developmental period?

Decreased levels of plasma nitrites/nitrates 
during postnatal ontogeny correlated with decreasing NO production by blood phagocytes. Therefore, the changes in NO production during ontogeny can be caused not only by endothelial NOS (NOS I) (as referred by Tsukahara et al. 1997a), but also by inducible NOS II expressed by blood phagocytes.

When experiments concerning ontogeny of RNS and the role of NO production during ontogeny are planned, not only endothelial (NOS I) but also inducible NOS II activity should be included. Constitutive NOS III expressed by neurons should not be omitted either, because changes in cerebral and cerebellar NOS III expression in guinea pigs and rats during ontogeny were found (Lizasoain et al. 1996).

Due to the ethical reasons, neither human nor animal studies include nitrites/nitrates status during prenatal period; however, some studies compared preterm and full-term animals, where preterm individuals probably reflect the nitrites/nitrates production before birth. Data from the literature indicate that preterm babies (Tsukahara et al. 1997a,b, Honold et al. 2000, Dzik et al. 2002) and preterm calves (Blum et al. 2001) produce higher amounts of nitrites/nitrates than full-term ones. This is in close relation to our findings that pig fetuses in the late phase of gestation (day 92 of gestation) had higher levels of nitrites/nitrates than newborn ones. It should however,be noted, that measurements of nitrites/ nitrates in humans were performed in urine and were recounted to urinary creatinine, whereas measurements in calves were performed directly in the blood plasma. It is questionable whether urinary nitrites/nitrates can fully reflect the levels of plasma nitrites/nitrates because it is known that renal function of neonates is different from that of adults (Hill and Lumbers 1988, Tsukahara et al. 1990). One publication, in which nitrites/nitrates were detected only in plasma, disagreed with all of the aforementioned results because no differences between preterm and full-term babies could be found (Biban et al. 2001).

No changes between prenatal and newborn production of NO by blood neutrophils were observed in our study, but the levels of nitrites/nitrates decreased during this period. Most plasma nitrites are excreted from the organism through urine. The possibility that the levels of plasma nitrites/nitrates can be increased independently from NO production by restricted removal of nitrites/nitrates from the blood stream should not be omitted.

Some authors have mentioned that increased NO production (expressed as increased level of nitrites/nitrates) is the mechanism of vascular tone regulation (Endo et al. 2001) because fetuses have lower blood pressure than postnatal individuals. Why plasma nitrites/nitrates are significantly higher on day 55 of gestation in comparison to day 92 of gestation is not clear, and whether the blood pressure is thus lower on day 55 than on day 92 of gestation remains unknown.

We can conclude that the production of RNS by peripheral blood neutrophils does not change during prenatal development. RNS production by peripheral blood phagocytes has decreasing trend during postnatal ontogeny (except for production of RNS by blood monocytes, which remained unchanged during the postnatal period). There are some similarities in development of RNS production by blood phagocytes and by plasma nitrites/nitrates but we cannot exactly determine if elevated plasma nitrites/nitrates in an earlier period are caused by NO production by peripheral blood phagocytes or if there is some other source of NO (e.g. endothelial cells or neurons). Thus the interpretation of these solitary data for understanding of natural immunity development cannot be exactly established. Further similar studies should be done to obtain more complete view of the RNS production during prenatal and early postnatal period of life.

\section{Conflict of Interest}

There is no conflict of interest.

\section{Acknowledgements}

This work was supported by grants Internal Grant Agency University of Veterinary and Pharmaceutical Sciences Brno (IGA VFU Brno) 14/05, Grant Agency of the Czech Republic 524/05/0267, MSM 6215712403 and Ministry of Agriculture of the Czech Republic 0002716201. The authors wish to thank Shannon Hatcher (Faculty of Biological Science, North Carolina State University, USA) for critical reading of the manuscript.

\section{References}

BIBAN P, ZANGARDI T, BARALDI E, DUSSINI N, CHIANDETTI L, ZACCHELLO F: Mixed exhaled nitric oxide and plasma nitrites and nitrates in newborn infants. Life Sci 68: 2789-2797, 2001. 
BLUM JW, MOREL C, HAMMON HM, BRUCKMAIER RM, JAGGY A, ZURBRIGGEN A, JUNGI T: High constitutional nitrate status in young cattle. Comp Biochem Physiol A 130: 271-282, 2001.

CASTILLO L, DEROJAS TC, CHAPMAN TE, VOGT J, BURKE JF, TANNENBAUM SR, YOUNG VR: Splanchnic metabolism of dietary arginine in relation to nitric oxide synthesis in normal adult man. Proc Natl Acad Sci USA 90: 193-197, 1993.

CHAKRAVORTTY D, HENSEL M: Inducible nitric oxide synthase and control of inracellular bacterial pathogens. Microb Infect 5: 621-627, 2003.

DZIK JM, DOBRZANSKA A, GRUSZFELD D, WALAJTYS-RODE E: Nitric oxide metabolites in the urine of fullterm and preterm infants. Pediatr Int 44: 368-375, 2002.

ENDO A, SHIMADA M, AYUSAWA M, MINATO M, TAKADA M, TAKAHASHI S, HARADA K, MASAOKA N, SATO K: Nitric oxide and endothelin 1 during postnatal life. Biol Neonate 70: 15-20, 1996.

ENDO A, IZUMI H, AYUSAWA M, MINATO M, TAKAHASHI S, HARADA K: Spontaneous labor increase nitric oxide synthesis during the early neonatal period. Pediatr Int 43: 340-342, 2001.

ERGENEKON E, GUCUYENER K, ERBAS D, KOC E, OZTURK G, ATALAY Y: Urinary nitric oxide in newborns with infections. Biol Neonate 78: 92-97, 2000.

FANG FC: Perspective series: host/pathogen interactions. Mechanisms of nitric oxide-related antimicrobial activity. J Clin Invest 99: 2818-2825, 1997.

FORSTERMANN U, GATH I, SCHWARZ P, CLOSS EI, KLEINERT H: Isoforms of nitric oxide synthase. Properties, cellular distribution and expressional control. Biochem Pharmacol 50: 1321-1332, 1995.

HILL KJ, LUMBERS ER: Renal function in adult and fetal sheep. J Dev Physiol 10: 149-159, 1988.

HONOLD J, PUSSER NL, NATHAN L, CHAUDHURI G, IGNARRO LJ, SHERMAN MP: Production and excretion of nitrate by human newborn infants: neonates are not little adults. Nitric Oxide 4: 35-46, 2000.

IGNARRO LJ, FUKUTO JM, GRISCAVAGE JM, ROGERS NE, BYRNS RE: Oxidation of nitric oxide in aqueous solution to nitrite but not nitrate: comparison with enzymatically formed nitric oxide from L-arginine. Proc Natl Acad Sci USA 90: 8103-8107, 1993.

ISCHIROPOULOS H: Biological tyrosine nitration: A pathophysiological function of nitric oxide and reactive oxygen species. Arch Biochem Biophys 356: 1-11, 1992.

KLEINBONGARD P, DEJAN A, LAUER T, RASSAF T, SCHINDLER A, PICKER O, SCHEEREN T, GODECKE A, SCHRADER J, SCHULZ R, HEUSCH G, SCHAUB GA, BRYAN NS, FEELISCH M, KELM M: Plasma nitrite reflects constitutive nitric oxide synthase activity in mammals. Free Radic Biol Med 35: 790-796, 2003.

KOVÁŘŮ F, KOVÁŘŮ H, FIŠEROVÁ A, MATALOVÁ E, ZELNÍČKOVÁ P, LANDA L, PALÍKOVÁ M: Fetal and postnatal development of T-lymphocyte subpopulations. Acta Vet Brno 71: 495-502, 2002.

LEE PT, HOLT PG, MCWILLIAM AS: Ontogeny of rat pulmonary alveolar macrophage function: evidence for a selective deficiency in IL-10 and nitric oxide production by newborn alveolar macrophages. Cytokine 15: 5357, 2001.

LIZASOAIN I, WEINER CP, KNOWLES RG, MONCADA S: The ontogeny of cerebral and cerebellar nitric oxide synthase in the guinea pig and rat. Pediatr Res 39: 779-783, 1996.

RHODES PM, LEONE AM, FRANCIS PL, STRUTHERS AD, MONCADA S: The L-arginine: nitric oxide pathway is the major source of plasma nitrite in fasted humans. Biochem Biophys Res Commun 209: 590-596, 1995.

SHERMAN MP, WONG VZ, AEBERHARD EE, FUKUTO JM, IGNARRO LJ: Amplified nitric oxide production by pulmonary alveolar macrophages of newborn rats. Redox Report 2: 309-316, 1996.

SUN J, ZHANG X, BRODERICK M, FEIN H: Measurement of nitric oxide production in biological systems using Griess reaction assay. Sensors 3: 276-284, 2003.

TREBICHAVSKÝ I, TLASKALOVÁ H, CUKROWSKA B, ŠPLÍCHAL I, ŠINKORA J, ŘEHÁKOVÁ Z, ŠINKORA M, POSPÍŠIL R, KOVÁŘ Ů F, CHARLEY B, BINNS R, WHITE A: Early ontogeny of immune cells and their functions in the fetal pig. Vet Immunol Immunopathol 54: 75-81, 1996.

TREBICHAVSKÝ I, ZÍDEK Z, FRANKOVÁ D, ZAHRADNÍČKOVÁ M, ŠPLÍCHAL I: Nitric oxide metabolites in gnotobiotic piglets orally infected with Salmonella enterica serovar Typhimurium. Folia Microbiol 46: 353$358,2001$. 
TSUKAHARA H, YOSHIMOTO M, SAITO M: Assesment of tubular function in neonates using urinary beta2microglobulin. Pediatr Nephrol 4: 512-514, 1990.

TSUKAHARA H, TAKEUCHI M, HATA I, HIRAOKA M, KOTSUI F, SUDO M, MAYUMI M: Assesment of emdogenous nitric oxide formation in newborns: measurement of urinary nitrite and nitrate concentrations. Biol Neonate 72: 322-326, 1997a.

TSUKAHARA H, HIRAOKA M, HORI C, TSUCHIDA S, HATA I, NISHIDA K, KIKUCHI K, SUDO M: Urinary nitrite/nitrate excretion in infancy: comparison between term and preterm infants. Early Human Dev 47: 51-56, 1997b.

VIERA L, YE YZ, ESTEVEZ AG, BECKMAN JS: Immunohistochemical methods to detect nitrotyrosine. Methods Enzymol 301: 373-381, 1999.

YANG D, LANG U, GREENBERG SG, MYATT L, CLARK KE: Elevation of nitrate level in pregnant ewes and their fetuses. Am J Obstet Gynecol 174: 573-577, 1996.

ZELNÍČKOVÁ P, KOVÁŘŮ H, PEŠÁK S, LOJEK A, MATALOVÁ E, ONDRÁČEK J, KOVÁŘŮ F: Postnatal functional maturation of blood phagocytes in pig. Vet Immunol Immunopathol 113: 383-391, 2006. 